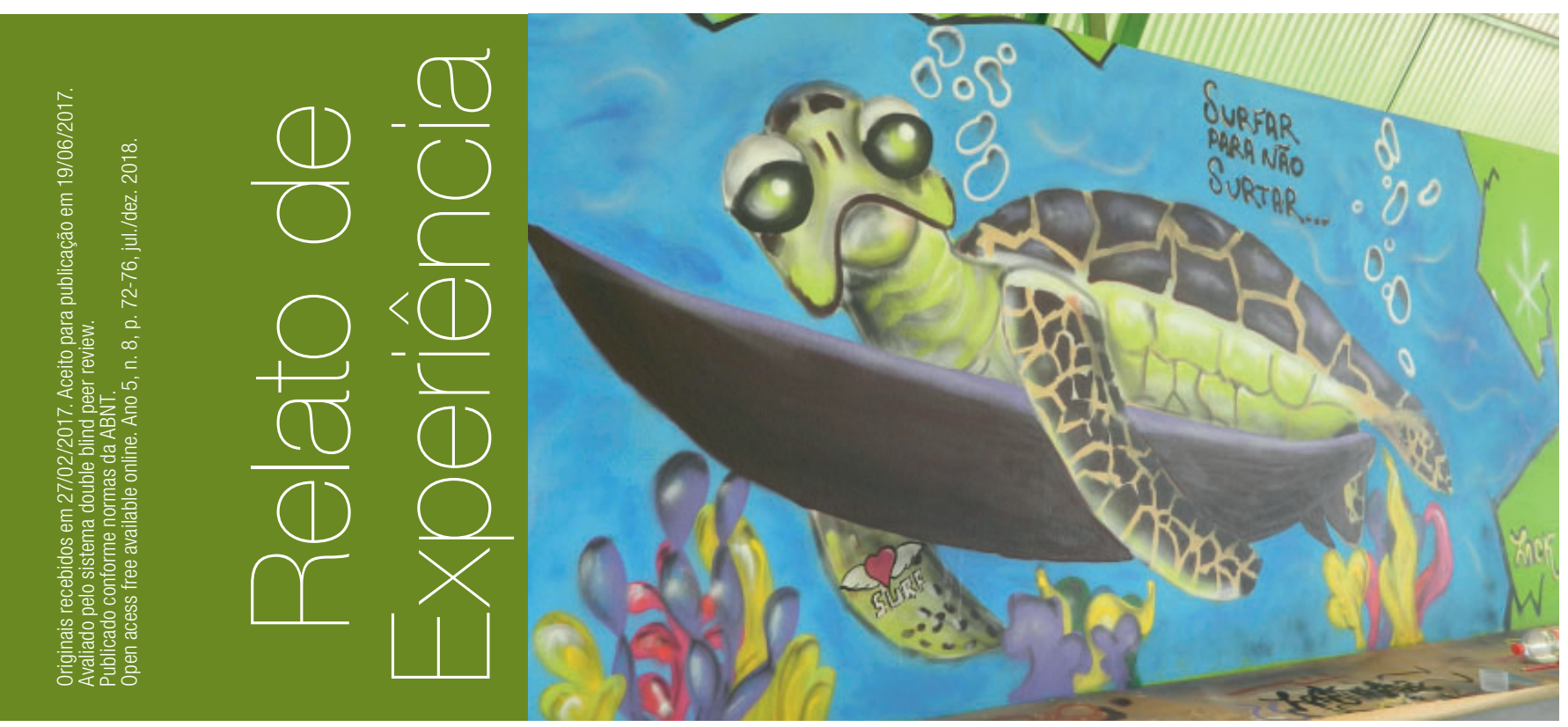

\title{
IFSC e arte urbana: interação entre cultura hip hop e escola
}

\author{
Fernanda Maria Trentini Carneiro 1 - \\ fernanda.trentini@ifsc.edu.br
}

\section{RESUMO}

0 presente relato de experiência tem o propósito de apresentar o processo de desenvolvimento de um projeto de extensão que aproximou a instituição de ensino da arte urbana e o seu resultado. Por meio dele houve a aproximação entre os bolsistas e os participantes (internos e externos), além da presença de artistas vinculados à cultura hip hop. Isso proporcionou a aplicação dos conhecimentos sobre 0 tema na prática, o reconhecimento do valor da arte e da educação como campo de conhecimento, de criação, de experimentação e de troca de experiências.

\section{PALAVRAS-CHAVE}

Educação. Projeto de Extensão. Grafite. Danças urbanas.

\section{ABSTRACT}

The present experience narrative aims to present the development process of an extension project that brought urban art and culture to an education institution and the results achieved. Due to the project, the scholarship student and the (inside and outside) participants got closer and beyond the artists' presence, the extension project provided the application of knowledge on the subject in practice, recognized the value of art and education as a field of knowledge, experimentation and exchange of experiences.

\section{KEYWORDS}

Education. Urban art. Graffiti. Street dance.

\footnotetext{
1 Professora de Artes do Instituto Federal de Santa Catarina - Câmpus Gaspar. Coordenadora do Projeto de Extensão "FSC e Arte Urbana: interação entre cultural hip hop e escola". Equipe executora: Anderson da Silva Honorato, Professor de Educação Física; Guilherme Jubett Quadros, Técnico Administrativo; Bolsistas de extensão: Eduarda Werner, Gabryelle Krüger, Marina Müller, Mateus Martins, Lucas Lima e Edson Junior.
} 


\section{Relato de experiência}

0 projeto de extensão teve como objetivo levar a cultura do hip hop, arte desenvolvida na cidade, para dentro do IFSC Câmpus Gaspar. 0 projeto de extensão foi contemplado pelo Edital Proex n 11/2016 - Mostra de Arte e Cultura Didascálico. A proposta foi reconhecer a arte do grafite e da dança urbana como espaço de criação e de experimentação artística e corporal, aproximando os participantes da arte urbana tão presente no dia a dia. A cidade é considerada por esta cultura como um suporte para a arte e para a integração do próprio local como obra de arte, por meio de intervenções e de instalações artísticas, conceitos presentes na arte contemporânea.

Observar a arte não significa "consumi-la" passivamente, mas tornar-se parte de um mundo ao qual pertencem essa arte e esse espectador. Olhar não é um ato passivo; ele não faz que as coisas permaneçam imutáveis. [...] é capaz de exercer qualquer influência estética no observador. A arte é um encontro contínuo e reflexivo com o mundo em que a obra de arte, longe de ser o ponto final desse processo, age como iniciador e ponto central da subsequente investigação do significado. ( ARCHER, 2001, p. 235-236)

Para a aproximação dessa experimentação artística, foram realizadas duas oficinas: a oficina de grafite (Figura 1), a qual foi ministrada pelos grafiteiros da região Adriel Giovanella (Zack), Nino Oni Jr e Felipe Crim (Coff), e a oficina de danças urbanas, ministrada pelo professor de dança Marlon Robert Glau. As oficinas foram abertas à comunidade interna e externa e oferecidas gratuitamente.

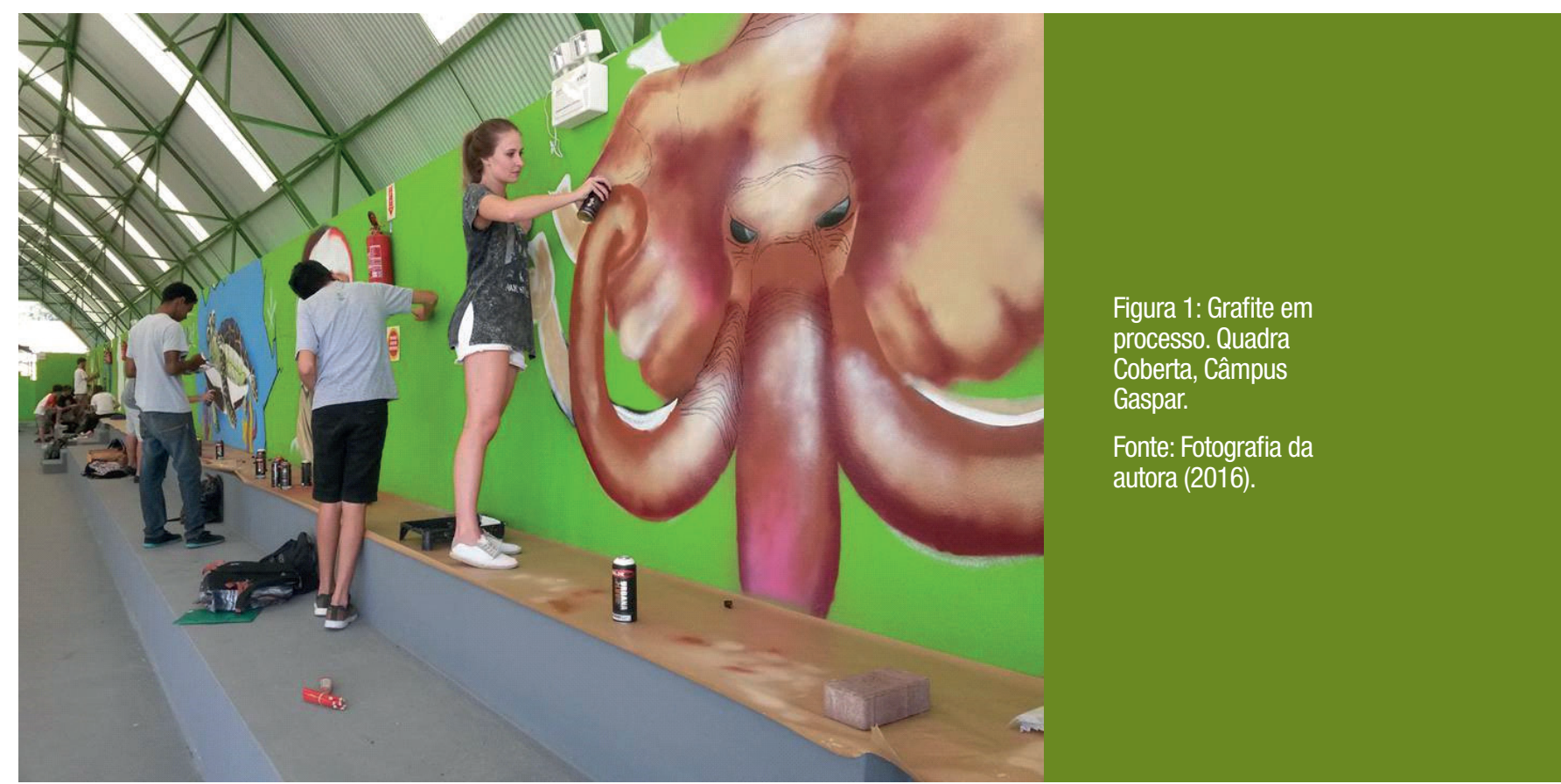

Dentro das unidades curriculares de Artes e de Educação Física, foram apresentados aos estudantes temas da arte contemporânea e linguagem corporal que os aproximaram de seu contexto, de seu dia a dia. Dentre esses temas, as intervenções, as instalações e as expressões corporais presentes na arte urbana são conceitos presentes em imagens identificadas e presenciadas na cidade.

Os bolsistas, alunos do câmpus, aplicaram esse conhecimento no projeto de extensão, de maneira a aproximar os conteúdos abordados em sala de aula aos participantes do projeto. Os alunos-bolsistas realizaram pesquisa de materiais e de ferramentas necessárias para a composição visual do grafite e para a criação e improvisação corporal de dança de rua da qual participaram (Figura 2).

Com a participação de artistas da região, os participantes do projeto tiveram a oportunidade de conhecer e compreender a arte como meio de comunicação e espaço de expressão, de 
experimentação e de criação em diálogo com questões pertinentes ao contexto em que estão inseridos. 0 contexto social é tomado como referência para a arte, pois é "uma construção social mutante no espaço, no tempo e na cultura, que hoje se reflete nas instituições, nos meios de comunicação, nos objetos artísticos, nos artistas e nos diferentes tipos de público" (HERNANDEZ, 2000, p.52).

Figura 2:

Experimentação de

materiais.

Fonte: Fotografia da autora (2016).

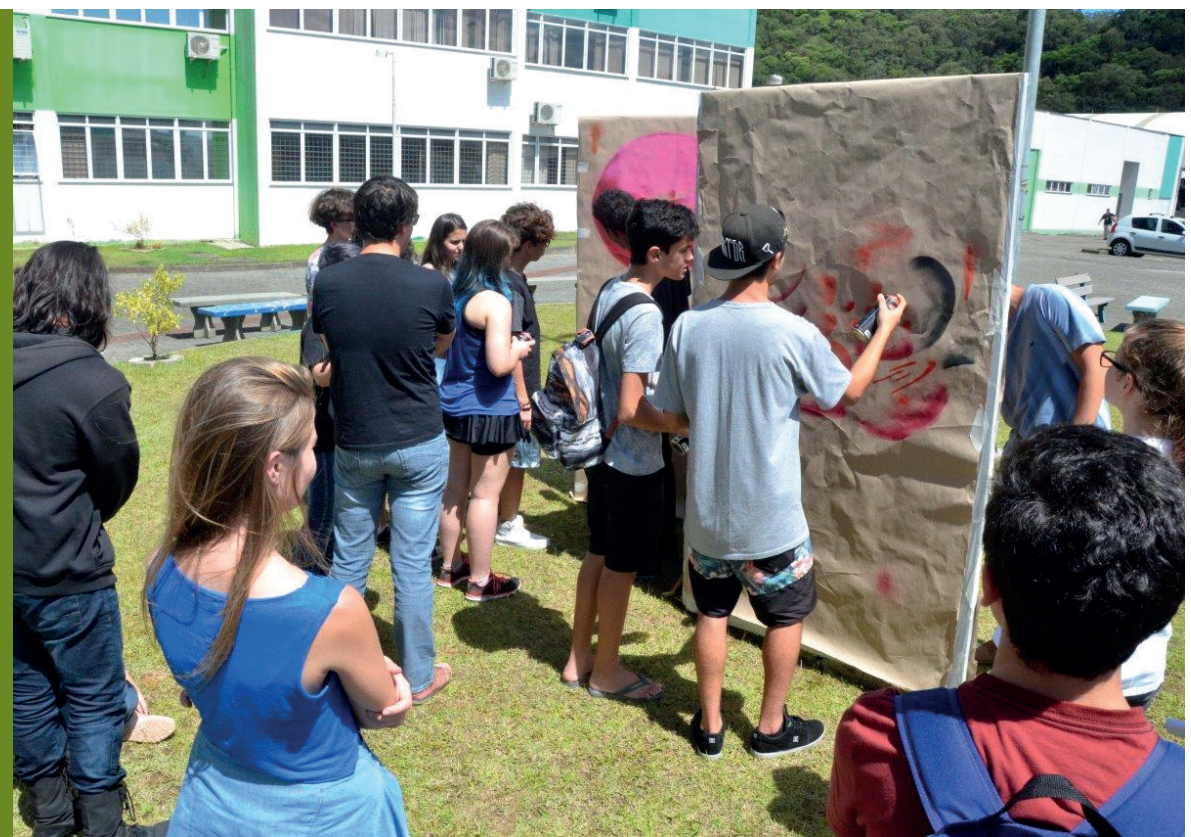

Durante os encontros, os bolsistas puderam ter autonomia para auxiliar os participantes na execução das oficinas. 0 diálogo entre bolsistas, artistas e participantes do projeto proporcionou a integração, a aproximação da cultura hip hop, o reconhecimento da importância da instituição e do trabalho em equipe. 0 encontro entre os envolvidos proporcionou um enriquecimento a partir da relação que se estabeleceu entre eles e o projeto, pois "quanto mais vivências têm, mais possibilidades terão de acumular experiências de vida significativas com a arte" (COUTINHO, 2002, p. 19).

A oficina de grafite envolveu, ao todo, seis encontros no período da tarde e contou com a participação da comunidade interna e externa. Foram realizadas inscrições para a participação nas oficinas, que contaram com a presença e articulação de artistas vinculados à arte urbana. Na oficina de grafite, primeiramente, foi feita uma apresentação sobre essa manifestação artística. Posteriormente houve a elaboração do esboço do grafite e a projeção nas paredes. Depois os participantes testaram os materiais, as possibilidades de criação e de composição. Por fim, o grafite foi realizado em dois espaços no Câmpus Gaspar: em uma parede externa do Bloco A, com a temática de pessoa, personagens e natureza; e em uma parede da arquibancada da quadra coberta, com o tema esporte e dança (Figura 3). Na oficina de danças urbanas, os participantes tiveram o contato com os primeiros passos para, posteriormente, experimentarem novos passos e composições sequenciais.

Percebemos que ambas as oficinas envolveram os participantes na elaboração, na execução e na finalização do projeto. Ao longo do processo, alguns participantes perceberam 0 valor existente no projeto de extensão por presenciarem vários momentos de interação. A importância dos bolsistas foi imprescindível para a realização das oficinas, pois, em diversos momentos, tomaram iniciativa e promoveram a orientação dos participantes em relação à construção dos grafites. Os participantes e os bolsistas demonstraram, dessa forma, autonomia e espírito de liderança, capacidade de cooperação, assim como, posicionamento crítico e reflexivo sobre o processo criativo .

Inicialmente foram registrados 15 inscritos para a oficina de grafite e 10 para a oficina de danças urbanas. Com o início da oficina de grafite, o número de inscritos aumentou para 30 
participantes e, ao longo do processo, vários participantes auxiliaram na sua elaboração e na finalização. Na oficina de danças urbanas houve, ao todo, ao final do projeto, 18 inscritos (Figura 4).

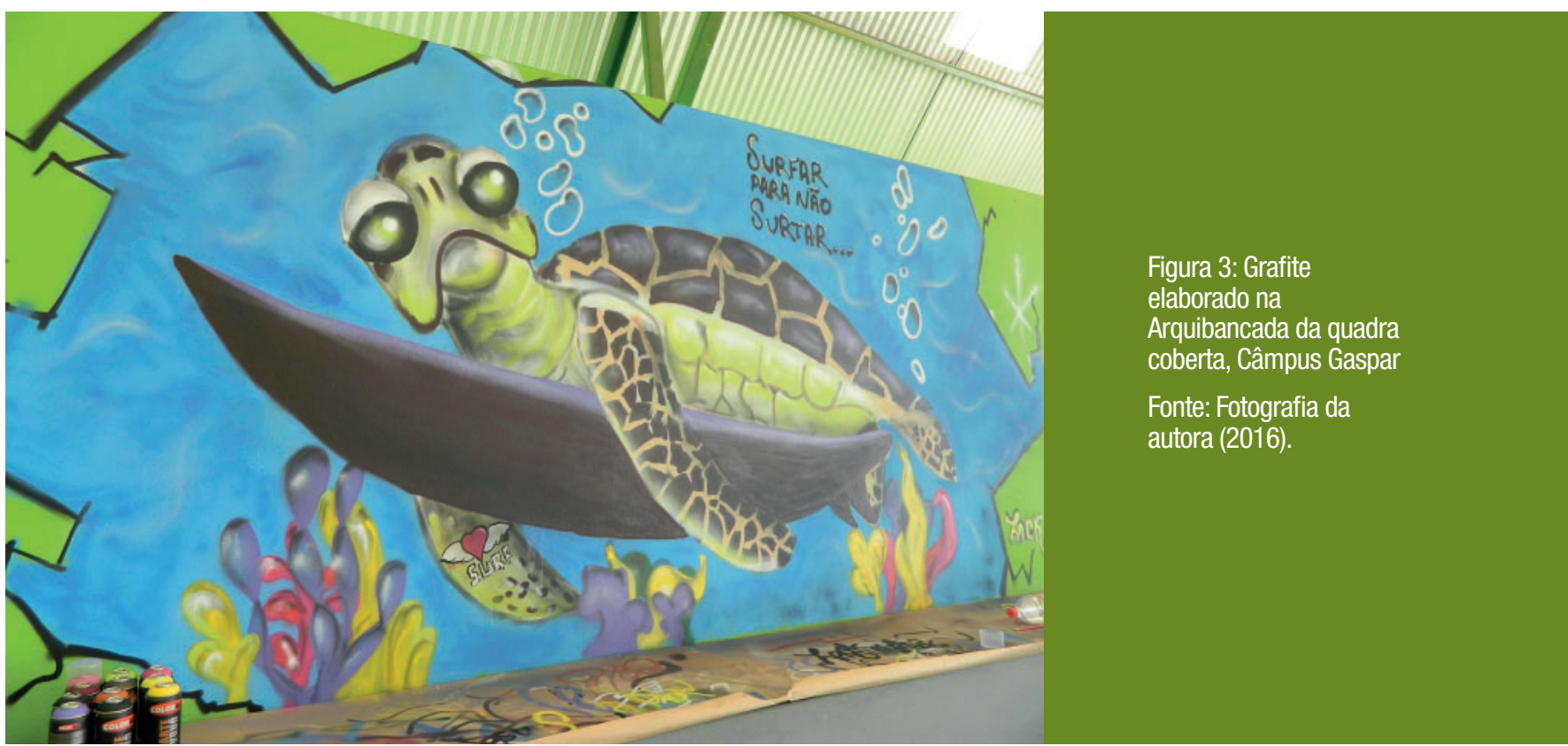

A partir das oficinas e da execução da prática artística, com o envolvimento dos bolsistas do projeto, artistas e participantes, o projeto colaborou com a formação de cidadãos críticos e reflexivos, visto que o contato com um público diferente, interno e externo ao Câmpus Gaspar, proporcionou uma interação e uma troca de experiências significativa. Dessa forma, a vivência com o processo de construção e desenvolvimento do projeto de extensão pôde levar o bolsista a motivar e a instigar os demais colegas à participação em projetos, tanto de pesquisa quanto de extensão.

Foi percebido por parte dos envolvidos durante as oficinas de danças urbanas e de grafite 0 desejo de continuidade do projeto, tanto por experimentação quanto por aprimoramento dos conhecimentos. A integração entre os participantes possibilitou o reconhecimento da arte urbana como um espaço de criação, de reflexão, de redução da desigualdade social e da diminuição do preconceito.

Diante dos resultados positivos identificados ao final das oficinas, o projeto apresenta possibilidade de ser replicado com a reedição das oficinas ofertadas e a ampliação de propostas vinculadas ao tema. Além das oficinas de danças urbanas e de grafite, o projeto permite o desdobramento por outras vertentes artísticas como a dança contemporânea, 0 cinema, o teatro e o esporte, permitindo múltiplas intervenções artísticas.

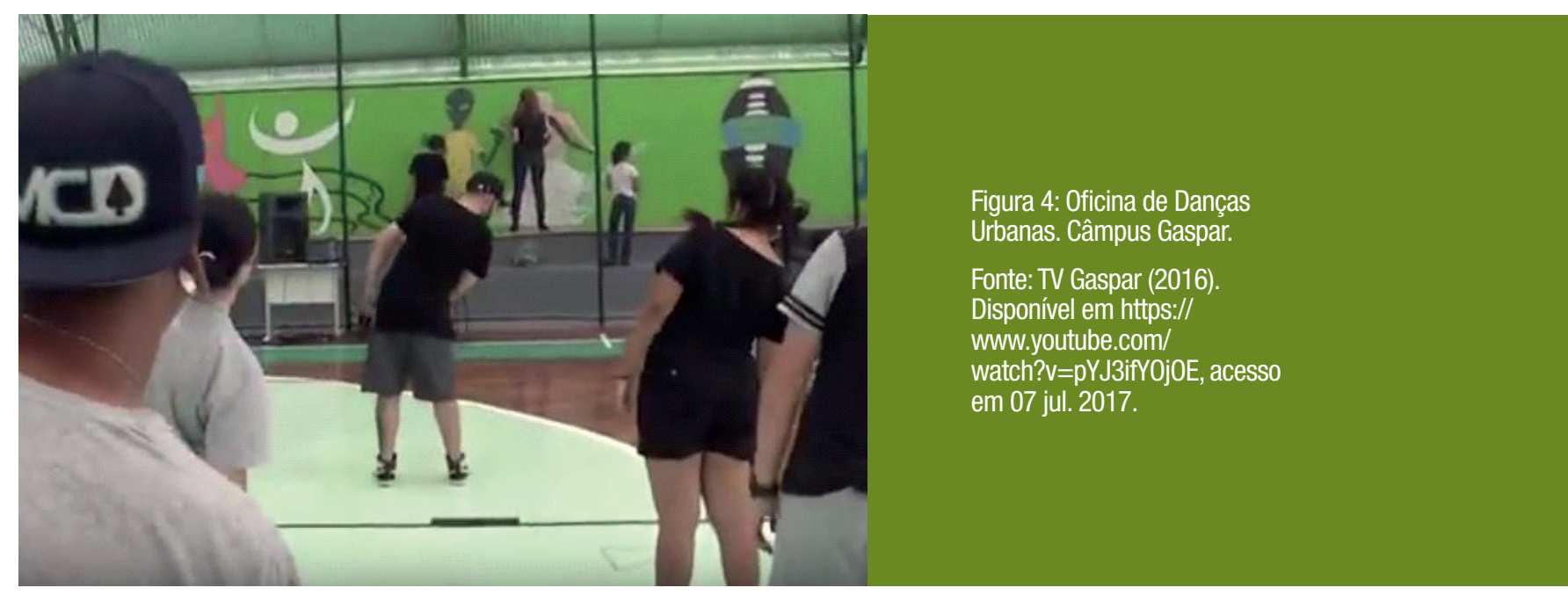




\section{Referências}

ARCHER, M. Arte contemporânea: uma história concisa. Tradução de Alexandre Krug e Valter Lellis Siqueira. São Paulo: Martins Fontes, 2001.

COUTINHO, Rejane. Vivências e experiências a partir do contato com a Arte. São Paulo: Sec. Est. Da Educação, 2002.

HERNANDEZ, Fernando. Cultura Visual, Mudança Educativa e Projeto de Trabalho. Porto Alegre: Artes Médicas, 2000. 